\title{
Microinvasive tumor endoresection in combination with ocular stereotactic radiosurgery
}

\author{
Oleg A. Sinyavskiy, MD, PhD, ${ }^{1}$ Roman L. Troyanovsky, MD, PhD, ${ }^{1}$ Pavel I. Ivanov, MD, PhD, ${ }^{2}$ \\ Alexandr S. Golovin, MD, ${ }^{1}$ Andrey V. Tibilov, MD, ${ }^{1}$ Svetlana N. Solonina, MD, PhD, ${ }^{1}$ \\ Anna M. Astapenko, MD, ${ }^{1}$ and Irina S. Zubatkina, $\mathrm{PhD}^{2}$
}

1Department of Ophthalmology, St. Petersburg Regional Hospital, and ²Department of Radiosurgery, Dr. Berezin Medical Centre, St. Petersburg, Russia

OBJECTIVE The use of Gamma Knife radiosurgery (GKRS) as monotherapy in the treatment of uveal melanoma (UM) allows clinicians to achieve high local tumor control with low recurrence but does not prevent secondary enucleation due to glaucoma in cases of large tumors. The authors analyzed indications for tumor endoresection (ER), the time interval between irradiation and surgery, and the features and results of performing ER for UM after GKRS.

METHODS Thirty-seven patients between 28 and 78 years of age (16 male and 11 female patients) with UM underwent GKRS with a dose of 70 to 80 Gy that was applied to the center of the tumor with complete immobilization of the eye during the procedure. Tumor resection with histological investigation was performed in 24 eyes (transscleral resection was performed in 3 eyes, and ER was performed in 21 eyes) at 3 to 97 days after GKRS, mainly during the first 2 or 3 weeks. As a rule, ER (21 eyes) was performed to treat large, centrally localized, or equatorial UMs with exudative macula-on retinal detachment that reduced vision. The average tumor height was $8.9 \mathrm{~mm}$, and the average width was $13.7 \mathrm{~mm}$ at the base. ER for UM included phacoemulsification, microinvasive vitrectomy with transretinal tumor resection, laser photocoagulation, and application of a temporary silicone oil tamponade. Seven patients received intraocular injections of inhibitors of angiogenesis for the prevention and treatment of radiation neuroretinopathy. The follow-up period ranged from 8 to 41 months.

RESULTS Preservation of the eyes without tumor recurrence was achieved in all 37 patients after GKRS (monotherapy and combined therapy). One patient died of liver metastases at 21 months after GKRS. In the ER group (21 eyes), drugresistant glaucoma with low visual acuity appeared in 4 eyes (19\%) with long-existing total exudative retinal detachment and delayed operations. Severe radiation neuroretinopathy with macular edema occurred in 4 of 21 cases (19\%). Intraocular injections of inhibitors of angiogenesis significantly decreased retinal edema. Residual rhegmatogenous retinal detachment was revealed in 1 eye (4.8\%). The conservation of the patient's primary vision or its improvement were observed in 11 eyes (52.4\%). Useful vision more than 0.1 was achieved in 12 cases (57\%), and more than 0.3 was achieved in 8 cases $(38 \%)$.

CONCLUSIONS As a result of this research, ER for UM after GKRS proved to be an effective method of combined eyeconserving treatment for large centrally localized or equatorial tumors at high risk of the emergence and development of toxic tumor syndrome. Perfect eye immobilization, timely ER, and multiple intraocular injections of inhibitors of angiogenesis saved not only the eye in all cases, but also useful vision in many cases. Close cooperation among radiosurgeons, ophthalmologists, and vitreoretinal surgeons is the key to effective treatment.

http://thejns.org/doi/abs/10.3171/2016.7.GKS161550

KEY WORDS melanoma; endoresection; stereotactic radiosurgery

$\mathrm{E}$ YE-CONSERVING methods for uveal melanoma (UM) treatment are currently used in more than $90 \%$ of cases. ${ }^{11}$ This was made possible thanks to better understanding of the ineffectiveness of enucleation in the prevention of metastasis ${ }^{3,16}$ and the advent of various types of stereotactic radiosurgery in recent decades, along with brachytherapy, that broaden the treatment options for large and centrally located UM. ${ }^{8}$ An important role is also played by technical progress in ophthalmic surgery.

Gamma Knife radiosurgery (GKRS) has been used for treating UM since 1996, mainly as a monotherapy.,10 This method achieves high local tumor control with low recur- 
rence but does not prevent secondary enucleation due to neovascular glaucoma,${ }^{15}$ which is a manifestation of toxic tumor syndrome during necrosis of a large UM. Thus, resection of the tumor after GKRS ${ }^{1,13,14}$ seems to be expedient for the preservation of the eye in patients at high risk of developing toxic tumor syndrome, especially in cases of large UMs with widespread exudative retinal detachment. ${ }^{6,12} \mathrm{We}$ analyzed endoresection (ER) indications, the duration between irradiation and surgery, and the features and results of combined treatment.

\section{Methods}

Thirty-seven patients (16 male and 11 female patients) between 28 and 78 years of age with UM underwent GKRS with complete immobilization of the eye during the procedure. Tumor resection with histological investigation was performed in 24 eyes (transscleral resection was performed in 3 eyes, and ER was performed in 21 eyes) at 3 to 97 days after GKRS, mainly during the first 2 or 3 weeks. ER was performed in large, centrally localized, or equatorial UM (21 eyes) with long-existing, exudative, macula-on retinal detachment, in most cases while the patient was in the prone position.

GKRS included the following steps: Leksell stereotactic frame fixation to the patient's head, immobilization of the affected eye, stereotactic MRI, treatment planning, irradiation of the tumor, and postprocedural MRI to assess the eye and tumor shifting. Attachment of the stereotactic Leksell G-Frame (Elekta Instruments) to the patient's head was performed under local anesthesia, followed by eye immobilization. The frame was moved forward as far as possible and rotated to bring the target much closer to the center of the stereotactic space. Complete immobilization of the eye was achieved by parabulbar injections of anesthetic solution and the use of suspensory sutures on the extraocular rectus muscles. Visualization of the lesion within the eye globe was attained with MRI using axial $1.0-\mathrm{mm}$ T1-weighted slices, as well as axial and coronal 2.0-mm T2-weighted slices and axial 1-mm CISS (constructive interference in steady state) images. All data were transferred into Leksell GammaPlan (Elekta Instruments) through the local network. Treatment planning and radiation dosimetry were done with the aim of conformal and selective coverage of the lesion with $40 \%$ to $60 \%$ of the prescription isodose line using the multiisocenter technique. The mean marginal dose was 35 Gy (range 30-40 Gy). One of the main aims was the avoidance of the incorporation of the optic nerve into the 8-Gy isodose area. We used plugging patterns to avoid administering the critical dose to the optic nerve. However, when the tumor was very close to the optic disc, it was impossible to avoid administering damaging irradiation doses to this critical structure. Radiosurgery was performed using the Leksell Gamma Knife model 4C and Perfexion (Elekta Instruments). Immediately after Gamma Knife treatment, postprocedural MRI was done to check eye shifting during the procedure.

The average tumor height was $8.9 \mathrm{~mm}$, and the average width was $13.9 \mathrm{~mm}$ at the base. ER for UM included phacoemulsification, microinvasive vitrectomy with transretinal tumor resection, retinal laser photocoagulation, and the application of a temporary silicone oil tamponade. In all cases, prior to or simultaneously with ER, phacoemulsification of the cataract with intraocular lens implantation was performed. The basis of ER for UM was sutureless microinvasive vitrectomy with outer diameters of $0.64 \mathrm{~mm}$ (23-gauge) and $0.51 \mathrm{~mm}$ (25-gauge) for the surgical instruments. Vitrectomy was carried out according to certain rules with complete vitreous detachment and the maximum possible removal of vitreum, including basal vitreum. To facilitate vitrectomy and reduce the risk of complications in the presence of exudative retinal detachment, at some stage a temporary tamponade of small amounts of perfluorocarbon liquid ("heavy fluid") was used. Only after total vitrectomy was it possible to proceed to the next stage of the operation. Resection of the tumor was performed after retinectomy in the projection of the tumor. The most effective strategy was to use the bimanual method with the use of endodiathermy, 23-gauge instruments, and an additional source of light. In most cases, the tumor tissue was removed down to the sclera. Endodiathermy, a transient increase in intraocular pressure, laser photocoagulation of the tumor base, controlled general hypotension, and the intravenous injection of tranexamic acid were used to prevent hemorrhage during the operation. After this, attachment of the retina was achieved during replacement of the irrigation solution with air, followed by laser retinopexy on the edges of retinectomy and the periphery of the retina. The operation was completed with application of the silicone oil tamponade to the vitreous chamber in 20 of 21 cases. As a rule, in the case of new or increased macular retinal edema, after ER of UM 7 patients were given 2 to 3 intraocular injections of inhibitors of angiogenesis per year for the treatment of radiation neuroretinopathy for times. The follow-up period ranged from 8 to 41 months (Table 1).

\section{Results}

Preservation of the eyes without tumor recurrence was achieved in all 37 patients after GKRS (monotherapy and combined therapy). In the ER group (21 eyes), after combined therapy the affected eyes were preserved without tumor recurrence in all cases $(100 \%)$ and with conservation or improvement of primary vision in 11 cases (52.4\%). Perfect immobilization of the eye during the entire irradiation procedure was confirmed by postprocedural MRI in all cases (Figs. 1-3).

One patient died of liver metastases at 21 months after GKRS. Drug-resistant glaucoma with low visual acuity appeared in 4 eyes (19\%), with long-existing retinal detachment and delayed operations. Iridectomy was performed on these patients after ER and the disappearance of exudative retinal detachment with stabilization of the intraocular pressure and glaucoma. Severe radiation neuroretinopathy with macular edema developed in 4 of 21 cases (19\%), which started 8 to 16 months after irradiation. There were minor symptoms of radiation neuroretinopathy in the other 11 cases without any significant decrease in vision. Intraocular injections of inhibitors of angiogenesis significantly decreased retinal edema in all 7 patients with the reduction or resolution of retinal hemorrhages and cotton-wool spots and improvement of vision (Figs. 4-7). 
TABLE 1. Patients who underwent ER of UM after GKRS

\begin{tabular}{|c|c|c|c|c|c|c|c|c|c|c|c|}
\hline $\begin{array}{l}\text { Case } \\
\text { No. }\end{array}$ & $\begin{array}{l}\text { Age (yrs), } \\
\text { Sex }\end{array}$ & $\begin{array}{c}\text { Tumor } \\
\text { Location }\end{array}$ & $\begin{array}{c}\text { Macular Retinal } \\
\text { Detachment } \\
\text { Before ER }\end{array}$ & $\begin{array}{l}\text { US Tumor } \\
\text { Size* }^{*}\end{array}$ & $\begin{array}{l}\text { TNM } \\
\text { Stage† }\end{array}$ & $\begin{array}{l}\text { Days Btwn } \\
\text { GKRS \& ER }\end{array}$ & $\begin{array}{c}\text { Vision } \\
\text { Before } \\
\text { ER }\end{array}$ & $\begin{array}{c}\text { Vision } \\
\text { After } \\
\text { ER }\end{array}$ & $\begin{array}{c}\text { Residual Retinal } \\
\text { Detachment } \\
\text { After ER }\end{array}$ & $\begin{array}{c}\text { Radiation } \\
\text { Neuroretinopathy }\end{array}$ & $\begin{array}{c}\mathrm{FU} \\
\text { (mos) }\end{array}$ \\
\hline 1 & $29, \mathrm{M}$ & PP & + & $12 \times 9.2$ & III & 4 & 0.2 & 1.0 & - & + & 41 \\
\hline 2 & $37, \mathrm{~F}$ & Equator & - & $10.2 \times 5.9$ & II & 3 & 1.0 & 1.0 & - & - & 38 \\
\hline 3 & $28, F$ & PP & + & $11.6 \times 5.7$ & II & 3 & 0.4 & 0.02 & - & ++ & 37 \\
\hline 4 & $69, F$ & Equator & + & $16.5 \times 10.6$ & III & 3 & 0.01 & 0.01 & - & + & 36 \\
\hline 5 & $68, F$ & Equator & + & $15.0 \times 11.5$ & III & 13 & 0.2 & 0.01 & + & + & 36 \\
\hline 6 & $59, F$ & Equator & - & $13.0 \times 9.0$ & III & 9 & 0.4 & 0.2 & - & ++ & 34 \\
\hline 7 & $57, \mathrm{~F}$ & Equator & - & $10.0 \times 3.1$ & II & 8 & 0.1 & 0.1 & - & - & 32 \\
\hline 8 & $56, F$ & Equator & - & $13.7 \times 11$ & III & 7 & 0.3 & 0.1 & - & - & 32 \\
\hline 9 & $50, M$ & Equator & + & $15.1 \times 11.6$ & III & 33 & 0.05 & 0.3 & - & + & 31 \\
\hline 10 & $62, \mathrm{M}$ & PP & + & $16.0 \times 6.0$ & III & 38 & 0.6 & 0.5 & - & + & 24 \\
\hline 11 & $42, \mathrm{M}$ & PP & - & $11.5 \times 5.1$ & II & 32 & 1.0 & 0.3 & - & ++ & 24 \\
\hline 12 & $68, M$ & PM & + & $16.0 \times 7.7$ & III & 20 & 0.01 & 0.09 & - & + & 16 \\
\hline 13 & $42, \mathrm{M}$ & Equator & + & $12.5 \times 8.7$ & III & 97 & 0.4 & 0.3 & - & + & 15 \\
\hline 14 & $70, \mathrm{~F}$ & PP & + & $11.0 \times 8.0$ & II & 59 & 0.01 & 0.005 & - & + & 14 \\
\hline 15 & $66, F$ & Equator & + & $13.0 \times 11.6$ & III & 26 & 0.1 & 0.7 & - & + & 12 \\
\hline 16 & $78, \mathrm{~F}$ & PM & + & $17.0 \times 9.1$ & III & 75 & 0.01 & 0.07 & - & + & 12 \\
\hline 17 & $53, \mathrm{M}$ & Equator & - & $11.0 \times 6.6$ & II & 19 & 0.6 & 0.1 & - & ++ & 10 \\
\hline 18 & $60, M$ & PM & + & $18.2 \times 14.4$ & IV & 33 & 0.01 & 0.05 & - & + & 10 \\
\hline 19 & $66, M$ & PM & + & $15.5 \times 8.0$ & III & 12 & 0.01 & 0.01 & - & - & 10 \\
\hline 20 & $63, M$ & PM & + & $12.5 \times 8.5$ & III & 9 & 0.1 & 0.5 & - & - & 9 \\
\hline 21 & $69, \mathrm{M}$ & PP & + & $15.7 \times 15.5$ & IV & 14 & 0.03 & 0.01 & - & - & 8 \\
\hline
\end{tabular}

$\mathrm{FU}=$ follow-up; $\mathrm{PM}=$ paramacular; $\mathrm{PP}$ = parapapillar; $\mathrm{US}$ = ultrasound; ++ = severe macular edema with a decrease in vision; + = minor presence of the indicated condition; - = absence of the indicated condition.

* Base $\times$ height is shown in millimeters.

† Determined using TNM Classification of Malignant Tumors, 7th Edition.

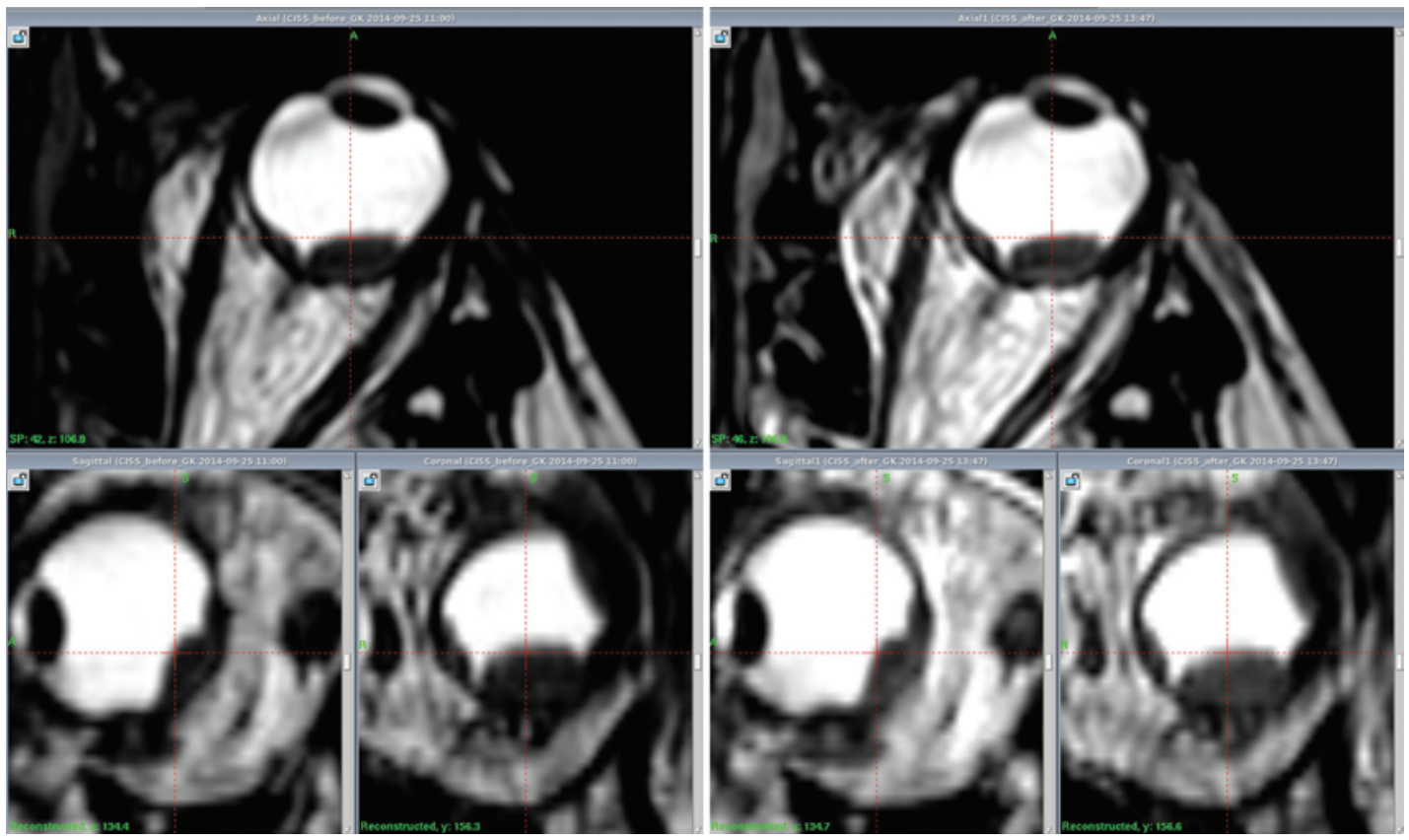

FIG. 1. MRI control of eye immobilization. Left: Before GKRS. Right: Immediately after GKRS. 


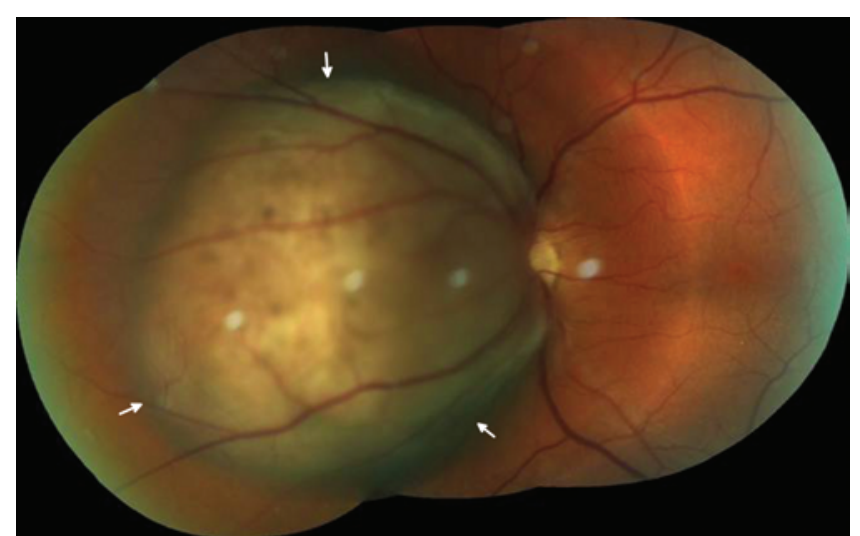

FIG. 2. Case 11. Fundus photograph showing the UM before treatment. The arrows indicate the tumor margins.

Three patients with rhegmatogenous retinal detachment after ER required additional operations, which led to retinal attachment in 2 cases. Residual rhegmatogenous retinal detachment remained in 1 eye $(4.8 \%)$. Finally, 12 $(57 \%)$ cases demonstrated useful vision more than 0.1 , and $8(38 \%)$ cases demonstrated useful vision more than 0.3 .

\section{Discussion}

In this study, we used GKRS with further ER of the tumor for combined eye-conserving treatment of large UMs at high risk of developing toxic tumor syndrome.

Since the first publications in 1996 on the application of GKRS for UM treatment, ${ }^{7,10}$ more than 3500 patients in the world have been treated, mostly without resection of the tumor. One of the benefits of this method is high local tumor control and low tumor recurrence. ${ }^{15}$ The important

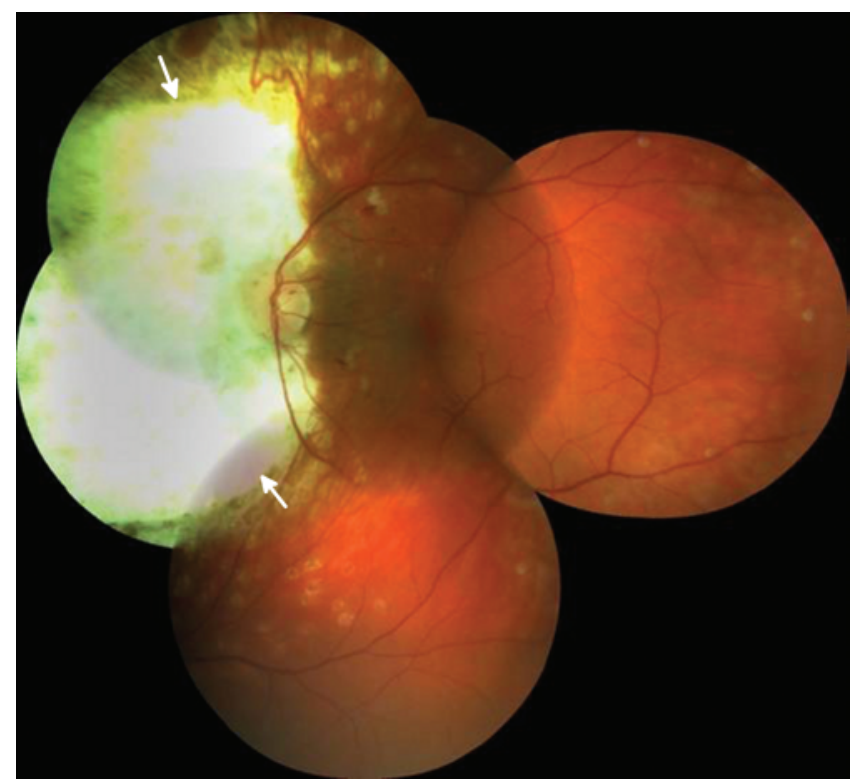

FIG. 3. Case 11. Fundus photograph showing scarring after ER of the UM. The arrows indicate the scar margins.

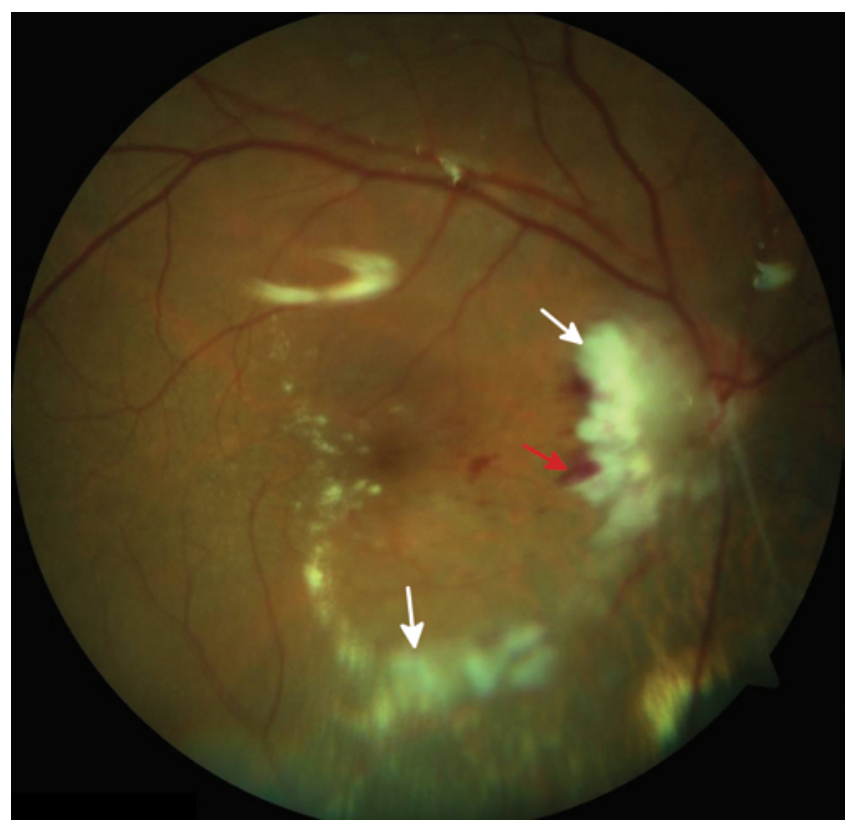

FIG. 4. Case 14. Fundus photograph showing radiation neuroretinopathy with macular edema at 8 months after GKRS. The white arrows indicate the cotton-wool spots, and the red arrow indicates retinal hemorrhage.

advantage of GKRS is that it is a 1-stage procedure. Its precision largely depends on immobilization of the eye. Other methods of stereotactic radiosurgery do not always provide perfect immobilization of the eye, especially during multiple sessions. However, monotherapy with GKRS for large melanomas leads to secondary enucleation within 5 years after irradiation in $31.9 \%$ of patients. ${ }^{15}$ The main reason for enucleation is secondary glaucoma, which can be considered a manifestation of toxic tumor syndrome that develops during tumor necrosis after irradiation ${ }^{3}$ in a relatively closed and confined space such as the eyeball. The removal of a large tumor seems promising for saving the eye, but the operation is very complex with a high risk of complications. The first ERs were performed by Peyman and Cohen. ${ }^{9}$ Subsequently, ERs were performed on centrally located tumors without preliminary irradiation by Damato et al. ${ }^{2}$ and García-Arumí et al. ${ }^{5}$ Currently, with progress in ophthalmic surgery, we are discussing methods of treatment that will allow saving not only the eye but also useful vision. ${ }^{1,12-14}$ This raises questions about the indications, the interval of time between irradiation and ER, the features of effective and safe surgery, and the treatment of radiation complications. It is obvious that ER should be performed on cases with the threat of emergence and the development of toxic tumor syndrome. We think that the main indication for ER after GKRS is longexisting, exudative, macula-on retinal detachment, which leads to the irreversible loss of vision. Usually, we see this in large UM cases with total exudative retinal detachment. In such cases, early ER is indicated at 1 to 3 weeks after GKRS since there is a high risk of not only vision loss, but also the loss of the eye due to the development of secondary neovascular glaucoma. The absolute indication for ER is hemophthalmos, which excludes reliable local tumor 


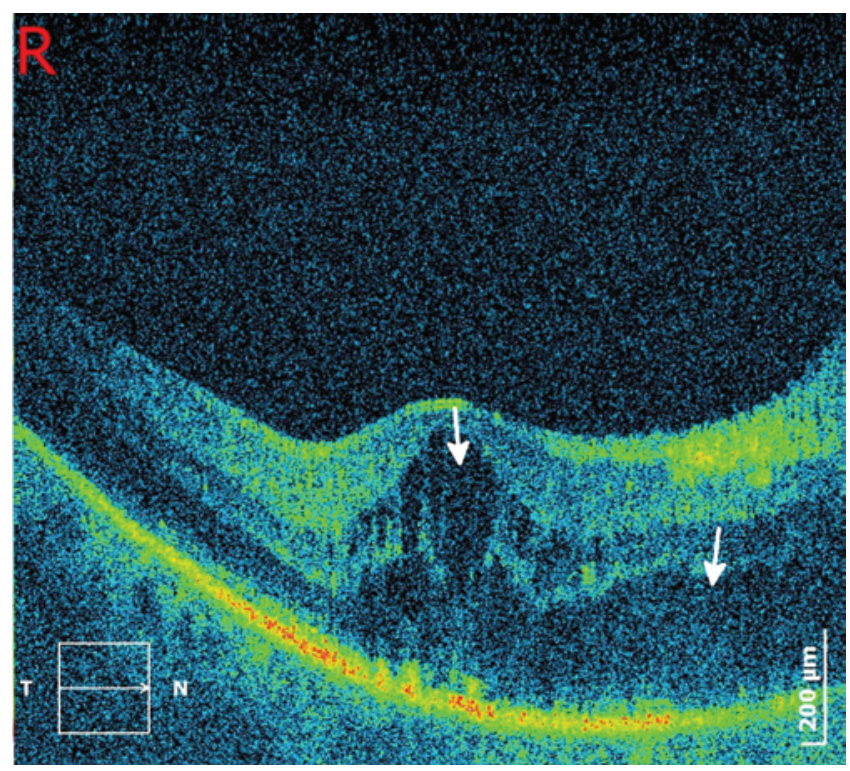

FIG. 5. Case 14. Optical coherence tomography showing radiation neuroretinopathy with macular edema at 8 months after GKRS. The arrows indicate a cavity with fluid in the retinal layers.

control. In cases of small local retinal detachment with macular involvement while the patient is in the prone position, ER is justified only in the absence of the resorption of the subretinal fluid in the macula at several weeks after GKRS. The operation should be effective and safe with adequate anesthesia. Presumably, we achieved significant results in terms of the conservation of vision in many cases and preservation of the eyes with the absence of tumor recurrence in all cases because of the special attention paid to immobilization of the eye. There was no eye displacement in our patients during GKRS. We assume that there is a direct connection between the immobilization of the eye during irradiation and the tumor recurrence rate. Perfect immobilization could be the reason for the absence of continuous tumor growth in our patients. This is confirmed by repeated histological studies of the tissues during silicone oil removal.

Intraocular injections of inhibitors of angiogenesis are currently widely used for the effective treatment of radiation neuroretinopathy. Continuous intravitreal anti-vascular endothelial growth factor therapy in patients with radiation maculopathy is well tolerated and preserves vision. In most cases, reductions or the resolution of retinal hemorrhages, cotton-wool spots, and retinal edema were noted for up to 10 years. ${ }^{4}$ Regular examinations of patients after GKRS are of great importance for the detection of the early signs of radiation injuries in the retina and optic nerve. In all of our 7 patients, injections were also very effective for reducing macular retinal edema, resolving hemorrhages and cotton-wool spots, and improving vision.

\section{Conclusions}

ER for UM after GKRS is an effective method of combined eye-conserving treatment for large, centrally local-

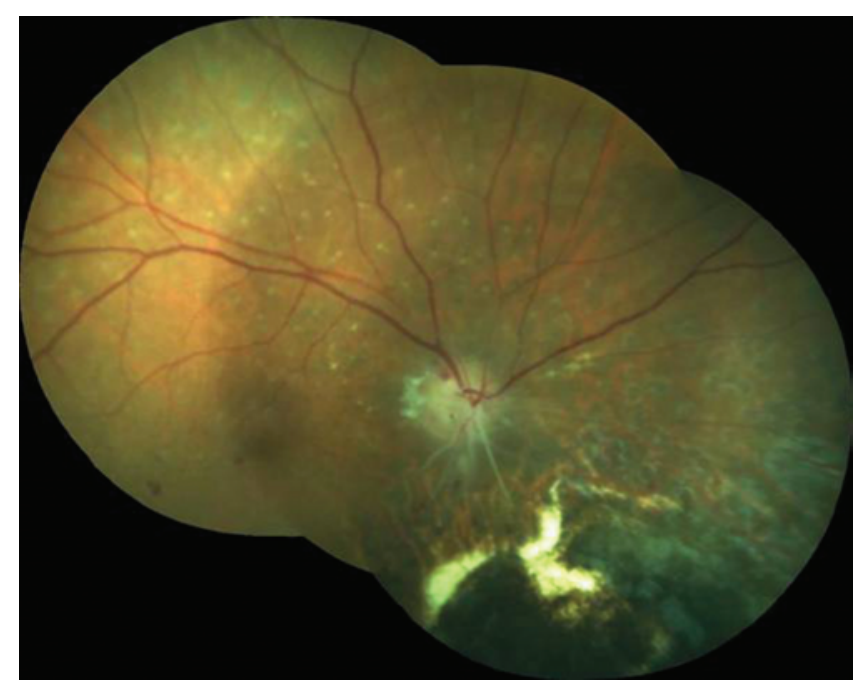

FIG. 6. Case 14. Fundus photograph showing the resolution of the cotton-wool spots and retinal hemorrhages in the macula and near the optic nerve after intravitreal injections of inhibitors of angiogenesis and silicone oil removal.

ized, and equatorial tumors at high risk of developing toxic tumor syndrome-a manifestation of which is a secondary glaucoma in patients with a background of longexisting, exudative, macula-on retinal detachment-and tumor necrosis. Perfect eye immobilization, timely radical $\mathrm{ER}$, and multiple injections of inhibitors of angiogenesis not only saved the eye in all cases, but also maintained vision in many cases. Close cooperation among radiosurgeons, ophthalmologists, and vitreoretinal surgeons is the key to effective treatment.

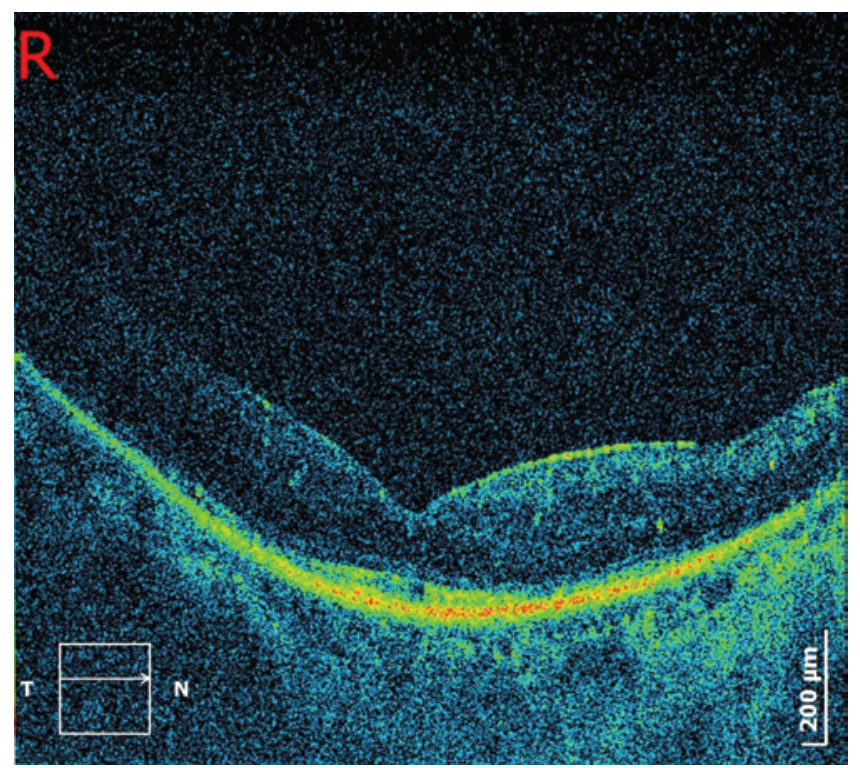

FIG. 7. Case 14. Optical coherence tomography showing the regression of macular edema with the resolution of the cavity with fluid in the retinal layers after intravitreal injections of inhibitors of angiogenesis and silicone oil removal. 


\section{References}

1. Biewald E, Lautner H, Gök M, Horstmann GA, Sauerwein W, Flühs D, et al: Endoresection of large uveal melanomas: clinical results in a consecutive series of 200 cases. $\mathbf{B r} \mathbf{~ J}$ Ophthalmol [epub ahead of print], 2016

2. Damato B, Groenewald C, McGalliard J, Wong D: Endoresection of choroidal melanoma. Br J Ophthalmol 82:213-218, 1998

3. Dinca EB, Yianni J, Rowe J, Radatz MW, Preotiuc-Pietro D, Rundle P, et al: Survival and complications following Gamma Knife radiosurgery or enucleation for ocular melanoma: a 20-year experience. Acta Neurochir (Wien) 154:605-610, 2012

4. Finger PT, Chin KJ, Semenova EA: Intravitreal anti-VEGF therapy for macular radiation retinopathy: a 10-year study. Eur J Ophthalmol 26:60-66, 2016

5. García-Arumí J, Zapata MA, Balaguer O, Fonollosa A, Boixadera A, Martinez-Castillo V: Endoresection in high posterior choroidal melanomas: long-term outcome. Br J Ophthalmol 92:1040-1045, 2008

6. Langmann G, Wackernagel W, Stücklschweiger G, Feichtinger K, Papaefthymiou G, Faulborn J: [Dose-volume histogram regression analysis of uveal melanomas after single fraction Gamma Knife radiosurgery.] Ophthalmologe 101:1111-1119, 2004 (Ger)

7. Marchini G, Gerosa M, Piovan E, Pasoli A, Babighian S, Rigotti M, et al: Gamma Knife stereotactic radiosurgery for uveal melanoma: clinical results after 2 years. Stereotact Funct Neurosurg 66 (Suppl 1):208-213, 1996

8. Nathan P, Cohen V, Coupland S, Curtis K, Damato B, Evans J, et al: Uveal Melanoma National Guidelines Summary, 2015. Cambridge, UK: Melanoma Focus, 2015 (http://melanomafocus.com/wp-content/uploads/2015/06/Uveal-Melanoma-National-Guidelines- Summary-v1.3.pdf) [Accessed July 8, 2016]

9. Peyman GA, Cohen SB: Ab interno resection of uveal melanoma. Int Ophthalmol 9:29-36, 1986

10. Rennie I, Forster D, Kemeny A, Walton L, Kunkler I: The use of single fraction Leksell stereotactic radiosurgery in the treatment of uveal melanoma. Acta Ophthalmol Scand 74:558-562, 1996

11. Seregard S, Pelayes DE, Singh AD: Radiation therapy: uveal tumors. Dev Ophthalmol 52:36-57, 2013

12. Schilling H, Bornfeld N, Talies S, Anastassiou G, Schüler A, Horstmann GA, et al: [Endoresection of large uveal melanomas after pretreatment by single-dose stereotactic convergence irradiation with the Leksell Gamma Knifefirst experience on 46 cases.] Klin Monatsbl Augenheilkd 223:513-520, 2006 (Ger)

13. Siniavskiy O, Troyanovsky R, Ivanov P, Golovin A, Solonina $\mathrm{S}$, Ilyushchenkov V, et al: [Resection of uveal melanoma after Gamma-Knife radiosurgery.] Oncosurgery 5:119-120, 2013

14. Troyanovsky R, Ivanov P, Siniavskiy O, Tibilov A, Solonina $\mathrm{S}$, Ilyushchenkov V, et al: Gamma-Knife in the eye's preservation treatment of uveal melanoma with or without tumor resection, in Congress of the European Society of Ophthalmology 2015 Abstract E-Book. Nottingham, UK: European Society of Ophthalmology, 2015, p 172, Abstract EP-ONC-0614 (http://www.abstractserver.com/soe2015/ ebook/index.html) [Accessed July 7, 2016]

15. Wackernagel W, Holl E, Tarmann L, Mayer C, Avian A, Schneider M, et al: Local tumour control and eye preservation after Gamma-Knife radiosurgery of choroidal melanomas. Br J Ophthalmol 98:218-223, 2014

16. Zimmerman LE, McLean IW: An evaluation of enucleation in the management of uveal melanomas. Am J Ophthalmol 87:741-760, 1979

\section{Disclosures}

The authors report no conflict of interest concerning materials and methods used in this study or the findings specified in this paper.

\section{Author Contributions}

Conception and design: Sinyavskiy, Troyanovsky, Golovin. Acquisition of data: Sinyavskiy, Ivanov, Golovin, Tibilov, Solonina, Zubatkina. Analysis and interpretation of data: all authors. Drafting the article: Sinyavskiy, Golovin. Critically revising the article: Sinyavskiy, Troyanovsky. Reviewed submitted version of manuscript: Troyanovsky, Ivanov, Golovin, Tibilov, Solonina, Astapenko, Zubatkina.

\section{Correspondence}

Oleg A. Sinyavskiy, Department of Ophthalmology, St. Petersburg Regional Hospital, St. Petersburg, Lunacharsky prosp., 47-49, 194291, Russia. email: sinol@ rambler.ru. 